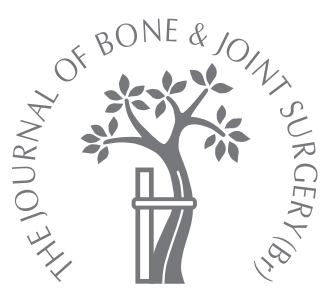
S. P. Krishnan,
J. A. Skinner,
W. Bartlett,
R. W. J. Carrington,
A. M. Flanagan,
T. W. R. Briggs,
G. Bentley
From the Royal
National
Orthopaedic
Hospital, Stanmore,
England

S. P. Krishnan, MRCS(Ed) Research Fellow

J. A. Skinner, FRCS(Orth),

Consultant Orthopaedic

Surgeon

W. Bartlett, MRCS(Ed),

Research Fellow

R. W. J. Carrington,

FRCS(Orth), Consultant

Orthopaedic Surgeon

A. M. Flanagan, MB, FRC

Path, PhD, Professor of

Histopathology

T. W. R. Briggs, MCh Orth,

FRCS(Orth), Consultant

Orthopaedic Surgeon

G. Bentley, DSc, ChM,

FRCS, F. Med Sci, Professor

of Orthopaedics

Royal National Orthopaedic

Hospital, Brockley Hill,

Stanmore, Middlesex HA7

4LP, UK.

Correspondence should be

sent to Mr S. P. Krishnan;

e-mail: shibupkrishnan@

yahoo.co.in

C2006 British Editorial

Society of Bone and

Joint Surgery

doi:10.1302/0301-620X.88B1.

$16796 \$ 2.00$

$J$ Bone Joint Surg [Br]

2006;88-B:61-4.

Received 31 May 2005;

Accepted after revision

6 September 2005

\section{Who is the ideal candidate for autologous chondrocyte implantation?}

We investigated the prognostic indicators for collagen-covered autologous chondrocyte implantation ( $\mathrm{ACl}-\mathrm{C}$ ) performed for symptomatic osteochondral defects of the knee.

We analysed prospectively 199 patients for up to four years after surgery using the modified Cincinnati score. Arthroscopic assessment and biopsy of the neocartilage was also performed whenever possible. The favourable factors for $\mathrm{ACl}-\mathrm{C}$ include younger patients with higher pre-operative modified Cincinnati scores, a less than two-year history of symptoms, a single defect, a defect on the trochlea or lateral femoral condyle and patients with fewer than two previous procedures on the index knee. Revision $\mathrm{ACl}-\mathrm{C}$ in patients with previous $\mathrm{ACl}$ and mosaicplasties which had failed produced significantly inferior clinical results. Gender $(p=0.20)$ and the size of the defect $(p=0.97)$ did not significantly influence the outcome.

Autologous chondrocyte implantation (ACI) is being used increasingly for the treatment of symptomatic osteochondral defects of the knee and has been shown to produce lasting benefits in patients followed for 11 years. ${ }^{1}$ Various studies have suggested it as an alternative to conventional techniques such as drilling, microfracture $^{2}$ and mosaicplasty ${ }^{3}$ with the advantage of reproducing a hyaline-like articular cartilage surface. Covering membranes used in these studies include periosteum (ACIP) ${ }^{1}$ and a porcine type I/III collagen membrane (ACI-C). ${ }^{4,5}$ The majority of the studies on the results of ACI have been performed on ACI-P.

We have for some years been using ACI-C instead of periosteum and have now analysed the factors which could influence the outcome after this procedure.

This study attempts to establish the prognostic factors which should guide the surgeon in selecting the patient who might gain maximum benefit from ACI-C and, ultimately, also to establish the cost-effectiveness of the technique.

\section{Patients and Methods}

A total of 199 patients (108 men, 91 women) underwent ACI-C for symptomatic osteochondral defects of the knee during a period of four years. Inclusion criteria were between 10 and 55 years of age, a defect size $>1 \mathrm{~cm}^{2}$ and the ability to follow our cartilage rehabilitation programme. ${ }^{3}$ Patients with known inflamma- tory joint disease and osteoarthritis were excluded from the study which was based on clinical, radiological and, where indicated, haematological and MRI examinations. All patients underwent arthroscopic assessment (first-stage ACI-C) in order to confirm that they satisfied the inclusion criteria and to exclude those with osteoarthritic changes. This study was approved by the Joint Research and Ethics committee of our hospital.

Patients were assessed clinically using the modified Cincinnati score ${ }^{6}$ pre-operatively and annually after surgery for four years. Arthroscopic assessment was performed at a variable interval between eight months and three years after ACI-C. Macroscopic assessment of the repair site using the International Cartilage Repair Society scoring system ${ }^{7}$ and biopsy of the implant, where possible, were performed.

The biopsy specimens were stained with either haematoxylin and eosin or safranin-O. All were assessed by the same pathologist (AMF) who was blinded to the patient's symptoms. The neocartilage was graded as hyalinelike, mixed fibrohyaline, fibrocartilaginous and fibrous. The possible prognostic factors analysed included the age and gender of the patient, the aetiology of the lesion, the duration of symptoms before ACI-C, the number of previous procedures on the index knee, the site, size and number of defects, the pre-operative functional scores and the International Cartilage Repair Society grade and histology of 
Table I. Summary of clinical results based on the modified Cincinnati score $^{6}$ at one to four years follow-up

\begin{tabular}{lrrllll}
\hline & \multicolumn{2}{l}{ Length of follow-up } \\
\cline { 2 - 7 } & 1 year & 2 years & 3 years & 4 years \\
\hline Number of patients & 199 & 141 & 82 & 48 \\
Excellent result (\%) & $71(35.7)$ & $50(35.5)$ & $27(32.9)$ & $15(31.3)$ \\
Good result (\%) & $60(30.1)$ & $35(24.8)$ & $18(22.0)$ & $14(29.1)$ \\
Fair result (\%) & $40(20.1)$ & $31(22.0)$ & $22(26.8)$ & $11(22.9)$ \\
Poor result (\%) & $28(14.1)$ & $25(17.7)$ & $15(18.3)$ & $8(16.7)$ \\
\hline
\end{tabular}

the neocartilage. These variables were compared with the modified Cincinnati score obtained at one year after ACI-C. The effect of the type of neocartilage was assessed against the modified Cincinnati scores at two, three and four years after operation.

The influence of the age of the patient on the outcome was analysed in three separate groups: $<20$ years, 21 to 40 years and $>41$ years at the time of surgery. Similarly, the number of previous procedures on the knee was divided into those with up to two operations, those with three to five and those with more than six. The influence of the size of the osteochondral defect on outcome was analysed in two separate groups as defects $<400 \mathrm{~mm}^{2}$ and those $>401$ $\mathrm{mm}^{2}$.

Statistical analysis. All statistical analyses were performed using the SPSS (version 11; SPSS Inc., Chicago, Illinois) and was supervised by the hospital's statistical advisor (RM).

Linear regression analysis was performed while investigating the relationship between numerical variables. Singlefactor analysis of variance (ANOVA) was performed while comparing non-numerical variables between groups, and chi-squared tests to compare categorical variables between groups. The level of significance was set at $\mathrm{p}<0.05$.

\section{Results}

The modified Cincinnati scores of 199 patients were analysed. Arthroscopic assessment of the graft repair site was carried out in 141 patients between eight months and three years post-operatively. Diagnostic histology was obtained from the biopsies of 92 patients.

The mean pre-operative modified Cincinnati score was 41.7 , improving to $62.0,61.2,58.0$ and 61.2 , respectively at one, two, three and four years after surgery. The maximum improvement in the clinical scores (20 points) occurred within the first year after ACI-C. Overall, the proportion of patients with excellent and good results was $65.8 \%$ at one year and $60.4 \%$ at four years (Table I).

Factors influencing results. Older patients had worse results $(\mathrm{p}<0.001)$. The mean modified Cincinnati scores were 76.7, 60.8 and 55.0, respectively, for those aged $<20$ years $(\mathrm{n}=28), 21$ to $40(\mathrm{n}=137)$ and $>41$ years $(\mathrm{n}=34)$. The proportion of patients with excellent and good clinical results were $85.7 \%$ for those aged $<20$ years, $64.2 \%$ for those aged 21 to 40 and $55.9 \%$ for those aged $>41$ years $(\mathrm{p}=0.04)$.
The improvement in the modified Cincinnati score was significantly higher for those patients with a high pre-operative score as opposed to those with a low score $(\mathrm{p}<0.001)$. A high pre-operative score also predicted a good result $(\mathrm{p}<0.001)$ on linear regression analysis.

Patients with knee symptoms for less than two years at the time of surgery showed better clinical results as opposed to those with more than two years of symptoms $185.7 \%$ and $60.5 \%$ excellent and good results, respectively, $\mathrm{p}=0.01)$. The mean modified Cincinnati score was 73.6 for those with symptoms for less than two years (43), 62.0 for those with symptoms for between two and five years (58), and 57 for those with symptoms for more than five years (98) $(\mathrm{p}=0.001)$.

Patients with three or more previous operations on the index knee showed significantly inferior clinical results $(\mathrm{p}=0.03)$. The proportion of patients with excellent and good results was $70.9 \%$ for those with fewer than two previous operations (134) and only $54.7 \%$ for those with three or more (65). Their mean modified Cincinnati scores were 64.8 and 55.8 , respectively $(\mathrm{p}=0.01)$.

The percentage of patients with excellent and good results was significantly low for those with a previously failed ACI and/or mosaicplasty $(15 ; 6.7 \%)$ compared with those following trauma $(88 ; 73.8)$, osteochondritis dissecans $(32 ; 67.7 \%)$ and chondromalacia patellae $(38,77.8 \%$; $\mathrm{p}<0.01)$. Of the 15 patients who underwent a revision ACI-C following a previously failed ACI or mosaicplasty, only one had a good result at one year. ACI-C after trauma, osteochondritis dissecans and chondromalacia patellae resulted in comparable clinical results.

The sites of cartilage implantation included the medial femoral condyle (78), lateral femoral condyle (25), patella single facet (53), patella multiple facets (24) and the trochlea (19). The frequency of excellent and good clinical results was significantly higher among ACI-Cs on the trochlea and lateral femoral condyle $(84.2 \%$ and $84 \%$, respectively, $\mathrm{p}=0.05$ ). Those with ACI-Cs on the medial femoral condyle, patella single facet and patella multiple facet had only $59.0 \%, 66 \%$ and $54.2 \%$ excellent and good results, respectively.

ACI-C was performed for multiple defects (a maximum of two) in 49 patients. They showed lower mean modified Cincinnati scores, 56.4, when compared with those with single site implantation (mean of $64.2 ; n=150$ ). This difference was significant $(\mathrm{p}=0.04)$.

The mean size of the osteochondral defect was 493.7 $\mathrm{mm}^{2}$ (100 to 1075; SD 299.7). A total of 99 patients had a defect size $<400 \mathrm{~mm}^{2}$ and the remaining 100 patients had a size $>401 \mathrm{~mm}^{2}$. There was no significant difference between their mean modified Cincinnati scores, which were 61.8 and 61.9 , respectively $(\mathrm{p}=0.97)$.

Gender did not significantly influence the improvement in clinical results $(p=0.20)$.

Influence of the histology of repair tissue on the results. Of the 92 biopsied, the number of patients with hyaline-like, 
mixed fibrohyaline, fibrocartilage and fibrous tissue was 25, 27, 38 and 2, respectively. Their International Cartilage Repair Society scores were 1 (excellent) or 2 (good) in $89.5 \%, 73.9 \%, 88.2 \%$ and $50 \%$, respectively ( $p>0.5$ ).

At one year, the proportion of patients with excellent and good clinical scores for the hyaline-like, mixed fibrohyaline and fibrocartilage groups were $72 \%, 88.9 \%$ and $71.1 \%$, respectively $(\mathrm{p}=0.27)$. One of the two patients with fibrous tissue repair also showed a good outcome with a modified Cincinnati score of 66.

The clinical scores at one and two years were not significantly different among the groups with hyaline-like, mixed fibrohyaline, or fibrocartilage repair tissue. The proportion of patients with excellent and good results remained comparable at two years $(63.2 \%, 72.7 \%$ and $64.5 \%$, respectively; $\mathrm{p}=0.48$ ). Both patients with fibrous tissue repair had a poor result at the two-year follow-up.

With time there was a tendency for the hyaline-like neocartilage group to show durable clinical scores while those with mixed fibrohyaline and fibrocartilaginous repair tissue showed a slight decline in their scores. These differences were not significant $(p=0.44)$ because of the small number of patients in each group; only eight, nine and 11 patients respectively in these three groups had reached the four-year follow-up. At three and four years post-implantation, the proportion of patients with excellent and good clinical scores was $71.4 \%$ and $75 \%$, respectively, for the hyalinelike neocartilage repair group, $53.3 \%$ and $44.4 \%$ for the mixed fibrohyaline group and $64.5 \%$ and $54.5 \%$ for the fibrocartilaginous repair group.

\section{Discussion}

Suitability for an articular cartilage implantation is decided after careful consideration of a patient's symptoms as well as by clinical, radiological and, where indicated, MRI examination. ${ }^{1,3}$ The final decision is made during the firststage diagnostic arthroscopy when the articular cartilage is harvested. Our study has identified the significant factors which can predict the outcome of the procedure and should guide the surgeon in selecting the most suitable candidates for ACI-C.

There is increasing debate about the expansion of indications for autologous chondrocyte implantation in the treatment of degenerative osteochondral lesions ${ }^{8,9}$ in the older age groups. Our study showed that increasing age had a strong negative influence on the functional results after ACI-C although the reasons for this are unclear.

Implanted chondrocytes are known to mature and proliferate for at least one year after implantation ${ }^{10}$ but it is uncertain for how long this continues. The maximum improvement in the mean modified Cincinnati scores in our study was seen in the first year after ACI-C, although a few patients continued to improve beyond one year. This may suggest that a clinically significant degree of maturation of neocartilage is less likely to occur after the first year.
Lesions on the medial femoral condyle had a significantly inferior clinical outcome when compared with those on the trochlea and lateral femoral condyle. The probability of an excellent or good result was $84 \%$ for those with lesions in the trochlea and lateral femoral condyle, and $59 \%$ in the medial femoral condyle. This difference was significant (95\% confidence interval $10 \%$ to $40 \%$ ). This implies that the probability of an excellent or good result was at least $10 \%$ greater for lesions in the trochlea and lateral femoral condyle compared with those in the medial femoral condyle.

Our study showed a tendency for the hyaline-like neocartilage group to produce a durable clinical outcome at the four-year follow-up when compared with those with mixed fibrohyaline, fibrocartilage and fibrous tissue repair. However, this was not statistically significant and further longterm follow-up is required to validate this observation.

Management of failed ACIs remain a problem in a young patient. Our study suggests that ACI-C after a failed mosaicplasty or ACI procedure is less likely to give favourable clinical results and should be discouraged. Whether it can be attempted as part of a combined procedure such as a high tibial osteotomy needs evaluation.

Current national guidelines within the United Kingdom ${ }^{11}$ recommend that ACI should be reserved for patients in whom previous treatments for articular cartilage defects have failed. These recommendations could both potentially increase the duration of symptoms and also increase the number of previous procedures on the knee. Both could adversely affect the clinical benefits of ACI-C.

Reconstruction of the contour of the femoral condyles is thought to be important for optimum functional results. ${ }^{12}$ Our study did not find any significant relationship between the size of the osteochondral defect and the clinical outcome. We routinely use bone grafts ${ }^{5}$ if the depth of the defect is greater than 8 to $10 \mathrm{~mm}$ but we did not assess the effect of depth on functional outcome because of the small numbers of patients involved.

Our study suggests that favourable factors for ACI-C include younger patients with higher pre-operative Cincinnati scores, a shorter duration of symptoms, a single defect, defects located on the trochlea and/or lateral femoral condyle and those with less than two previous procedures on the index knee. We cannot recommend ACI-C in patients with previously failed ACIs and mosaicplasties until the results of revision ACI-C with combined procedures such as tibial osteotomy are known.

\footnotetext{
We wish to thank Dr Rlchard Morris for his assistance with statistical analysis. No benefits in any form have been received or will be received from a commercial party related directly or indirectly to the subject of this article.
}

\section{References}

1. Peterson L, Brittberg M, Kiviranta I, Akerlund EL, Lindahl A. Autologous chondrocyte transplantation: biomechanics and long term durability. Am J Sports Med 2002;30:2-12.

2. Peterson L, Minas T, Brittberg M, et al. Two- to 9-year outcome after autologous chondrocyte transplantation of the knee. Clin Orthop 2000;374:212-34. 
3. Bentley G, Biant LC, Carrington RWJ, et al. A prospective randomised comparison of autologous chondrocyte implantation versus mosaicplasty for osteochondral defects in the knee. J Bone Joint Surg [Br] 2003;85-B:223-30.

4. Haddo $\mathbf{0}$, Mahroof $\mathbf{S}$, Higgs $\mathbf{D}$, et al. The use of chondrogide membrane in autologous chondrocyte implantation. Knee 2004;11:51-5.

5. Bartlett W, Gooding CR, Carrington RWJ, et al. Autologous chondrocyte implantation at the knee using a bilayer collagen membrane with bone graft: a preliminary report. J Bone Joint Surg [Br] 2005;87-B:330-2.

6. Barber-Westin SD, Noyes FR, McCloskey JW. Rigorous statistical reliability, validity, and responsiveness testing fo the Cincinnati knee rating system in 350 subjects with uninjured, injured, or anterior cruciate ligament-reconstructed knees. Am J Sports Med 1999;27:402-16.

7. Brittberg M, Winalski CS. Evaluation of cartilage injuries and repair. J Bone Joint Surg $[$ Am] 2003;85-A(Suppl 2):58-69.
8. Baker CL Jr, Ferguson CM. Future treatment of osteoarthritis. Orthopedics 2005;28 (Suppl):227-34

9. Minas T. Autologous chondrocyte implantation in the arthritic knee. Orthopedics 2003;26:945-7.

10. Briggs TWR, Mahroof S, David LA, et al. Histological evaluation of chondral defects after autologous chondrocyte implantation of the knee. J Bone Joint Surg [Br] 2003;85-B:1077-83.

11. National Institute of Clinical Excellence. Guidance on the use of autologous chondrocyte transplantation for full thickness cartilage defects in knee joints: technology appraisal guidance No. 16. London: National Institute of Clinical Excellence December 2000

12. Sharpe JR, Ahmed SU, Martin R, Fleetcroft JP. The treatment of osteochondral lesions using a combination of autologous chondrocyte implantation and autograft: three year follow-up. J Bone Joint Surg [Br] 2005;87-B:730-5. 